\title{
Aproximación a los estudios sobre fútbol peruano y comunicación: prensa escrita, radio y televisión
}

\section{Approximation to studies on Peruvian soccer and communication: printed press, radio and television}

\author{
Alonso Roberto Pahuacho Portella ${ }^{1}$ \\ Recibido: 12-09-2017 - Aceptado: 12-12-2017 \\ DOI: https://doi.org/10.26441/RC17.1-2018-A6
}

\begin{abstract}
RESUMEN: El presente artículo ofrece un recorrido a través de diversos textos -de los últimos cincuenta años de investigación- sobre el rol y desarrollo del fútbol peruano y sus vínculos con los estudios de comunicación. Se busca ponderar el rol que han desempeñado los medios deportivos en la construcción de la realidad social peruana, específicamente para el caso de la historiografía del fútbol en ese país. A través de una revisión detallada de tres fuentes comunicacionales (prensa escrita, radio y televisión), se observa una marcada tendencia desde la academia peruana por la investigación del balompié y las Comunicaciones tomando como fuente a la prensa escrita y televisión, omitiendo a la radio. Futuras pesquisas deberán también abocarse a aspectos visuales, nuevas tecnologías y audiencias.
\end{abstract}

Palabras Clave: fútbol peruano; medios de comunicación; identidades nacionales; periodismo deportivo.

\begin{abstract}
This article offers a journey through various texts -from the last fifty years of researchabout the role and development of Peruvian soccer and its links with communication studies. The aim is to ponder the role played by sports media in the construction of Peruvian social reality, specifically in the case of football historiography in that country. Through a detailed review of three communication sources (written press, radio and television), we see a marked tendency from the Peruvian academy for the investigation of football and communications, taking as a source the written press and television, omitting the radio. Future research should also focus on visual aspects, new technologies and audiences.
\end{abstract}

Key Words: peruvian soccer; mass media; national identities; sports journalism.

1 Alonso Roberto Pahuacho Portella es Licenciado en Periodismo y Magíster en Estudios Culturales por la Pontificia Universidad Católica del Perú. Actualmente cursa el doctorado en Medios, Comunicación y Cultura en la Universidad Autónoma de Barcelona. Sus investigaciones se centran en la sociología del fútbol, las narrativas nacionalistas y la teoría psicoanalítica en su vertiente lacaniana. alonso.pahuacho@e-campus.uab.cat, https:// orcid.org/0000-0001-8783-7978 


\section{Introducción}

La historiografía sobre el fútbol y medios de comunicación en el Perú es un campo en sus primeras etapas de desarrollo y con mucho trabajo aún por desarrollar para presentar un panorama concreto y vasto, a diferencia de lo que ocurre en otros países del continente, como Argentina o Brasil. En nuestro país, gran parte de la producción académica se ha realizado de la mano de científicos sociales y periodistas, quienes entendieron la importancia de este deporte en un contexto como el peruano, tan heterogéneo y complejo, pero útil para abordar cualquier estudio que se arrope bajo el paraguas de la interdisciplinariedad académica. Esta variedad de disciplinas, incluyendo la Sociología, Antropología, Historia y las Comunicaciones, sintetiza la perspectiva desde donde se ha abordado el fenómeno del fútbol para entenderlo como algo más que solo un deporte, sino una parte fundamental de la identidad nacional peruana.

Nuestra hipótesis de trabajo postula que los estudios que enlazan al fútbol con las Comunicaciones se originan a raíz de la profesionalización del Periodismo en las universidades peruanas alrededor de la primera mitad del siglo XX y también a los éxitos deportivos de nuestra selección nacional en la década de 1970. Estos trabajos pioneros sentarán las bases para la proliferación de nuevas investigaciones con la llegada del nuevo siglo, gracias a las posibilidades tecnológicas que ofrecía el Internet y el acceso a nuevas fuentes de información. En ese contexto, es el ámbito de la prensa escrita la que ha recibido mayor atención por parte de los investigadores, tomándola como fuente principal en la mayoría de trabajos.

Como objetivo general, nos proponemos comprender la forma en que la academia peruana ha estudiado el fenómeno del fútbol, haciendo hincapié en la arista comunicacional. Nos detendremos a examinar trabajos que exploren las dinámicas de la prensa escrita, la radio y la televisión con el balompié. En tanto, los objetivos específicos son analizar el tratamiento científico que se le ha dado al fútbol en nuestro país y determinar cómo se ha construido el estado de la cuestión respecto a este deporte (en qué aspectos del saber se ha hecho foco). También nos interesa contrastar los resultados de las distintas pesquisas, enfatizando su diversidad en cuanto el objeto de estudio o tipo de medio examinado (escrito, radial o televisivo), a fin de poder extrapolarlo con casos internacionales.

\section{Metodología}

El estudio de la bibliografía se realizará a partir del análisis de una serie de elementos que nos permitirán rescatar las tesis fundamentales de las pesquisas sobre fútbol desarrolladas dentro de nuestra academia desde mediados del siglo XX. Para ello, en cada trabajo presentaremos el nombre del autor, la fecha de publicación, de qué tipo de documento se trata (tesis, artículo, ponencia, libro, etc.) y el método de investigación elegido. Debemos aclarar en este punto que estamos considerando dentro de los medios de comunicación 
actuales a la prensa escrita, radio y televisión. Es sobre estas tres aristas que discutiremos la historiografía peruana ${ }^{2}$ que las vincula con el deporte del fútbol. Revisaremos trabajos estrictamente de carácter científico, como artículos, ensayos compilados en libros académicos, libros académicos, ponencias y tesis de grado o posgrado. Los textos periodísti$\cos$ y literarios (columnas, entrevistas, reportajes, crónicas, cuentos, etc.) han quedado al margen dado nuestro objetivo inicial: evaluar la situación actual de la producción científico-académica referida a los medios y el fútbol ${ }^{3}$.

Respecto a la estructura del artículo, este consta de cuatro partes. En primer término, realizaremos un breve repaso por la historia del fútbol peruano desde finales del siglo XIX hasta comienzos del XXI. Más adelante, revisaremos el rol crucial que tienen los medios en la actualidad como constructores de identidades y representaciones sociales. A continuación, examinaremos detalladamente la historiografía peruana dedicada al estudio del fútbol desde el enfoque de las comunicaciones; esto es, pesquisas que hayan tenido como objetivo de estudio al balompié desde una perspectiva interdisciplinaria que parta de los medios de comunicación para tratar de comprenderlo. Finalmente, concluiremos con una discusión de la situación actual de este campo de estu- dio, sus debilidades y desafíos pero, sobre todo, sus posibilidades para futuros estudios.

\section{Una breve historia del fútbol peruano}

Los orígenes de la práctica del fútbol en el Perú se remontan a las últimas décadas del siglo XIX, cuando marineros ingleses desembarcaban en el puerto del Callao y disputaban partidos contra entusiastas jóvenes limeños y chalacos. Fueron estos inmigrantes extranjeros los que fundaron los primeros clubes de fútbol tales como el Lima Cricket. Luego el deporte se fue popularizando y los propios peruanos fundaron su club, el Unión Cricket. Era común que estos dos equipos se enfrentaran en lo que se vivía como una verdadera competencia entre peruanos contra ingleses. El historiador Gerardo Álvarez (2001), en la investigación producto de su tesis de licenciatura sobre la difusión de la práctica del balompié en la capital peruana, afirma que con la llegada del nuevo siglo se van fundando nuevos clubes y la competencia deportiva fue creciendo en nuestro país. El Estado, a través de las escuelas y los municipios, jugó un papel fundamental en esa propagación, pues se consideraba que este deporte cultivaba los ideales modernos y de culto a la preparación física, influencia del positivismo de aquellos años.

\footnotetext{
2 Al referirnos a "historiografía peruana", tomamos en cuenta únicamente a investigadores de esa nacionalidad que hayan desarrollado trabajos respecto al fútbol y su vínculo con los medios de comunicación, ello para ponderar el aporte de la academia peruana dentro de éste campo de estudio.

3 Un buen libro que compila una muestra representativa de gran parte de la producción periodística y literaria peruana sobre nuestro fútbol de los últimos veinte años es Bien Jugado (2011), editado por Jorge Eslava.
} 
La primera selección nacional peruana recién se conforma para disputar el Campeonato Sudamericano de Selecciones en 1927. Antes, países como Argentina, Uruguay o Chile nos habían tomado la delantera, afiliándose a instituciones que hasta la fecha perduran como la FIFA o la Confederación Sudamericana de Fútbol (Conmebol). Perú sólo le ganó a Bolivia en aquella oportunidad, lo que significó su primer triunfo oficial a nivel de selecciones en el torneo que se disputó en Lima. Conforme la práctica del fútbol se iba difundiendo en territorio peruano, su selección iba ingresando al ámbito de la competencia internacional participando, aunque no con mucha fortuna, en los Campeonatos Sudamericanos de 1929 y 1935, la Copa del Mundo de 1930 y los Juegos Olímpicos de Berlín en 1936.

En 1939, el Perú conquista su primer título a nivel continental, consagrándose en el Campeonato Sudamericano de Selecciones disputado en Lima. Las figuras rutilantes de aquel equipo eran Teodoro "Lolo" Fernández y el arquero Juan Valdivieso. Un año antes, el equipo peruano había conseguido otro logro: los Juegos Bolivarianos que se realizaron en Colombia. Allí Perú derrotó categóricamente a las selecciones de Colombia, Ecuador, Bolivia y Venezuela para llevarse la medalla de oro. Años más tarde, la selección conseguiría uno de sus triunfos más recordados al golear 4-1 a Inglaterra en 1959 con una gran actuación del delantero Juan el Loco Seminario, quien marcó un triplete.
La década del 70 es considerada para muchos hinchas como la mejor del fútbol peruano. El Perú consiguió su clasificación a dos Mundiales y se proclamó, una vez más, campeón sudamericano en 1975. Aquella generación estaba encabezada por Teófilo Cubillas, Héctor Chumpitaz, Cesar Cueto, entre otras figuras. El país, en aquella década, estuvo bajo el control de una dictadura militar de izquierda que utilizó al fútbol de un modo nacionalista, aprovechando su gran popularidad entre la gente (Aguirre, 2013). La selección peruana asistió otra vez al Mundial de España 1982, lo que sería su última clasificación hasta la fecha. No obstante, la suerte no le sonrió y se fue eliminado sin haber ganado un solo partido.

Entre finales de los 80 y principios de los 90 la selección peruana atravesó una profunda crisis de resultados a consecuencia de la falta de renovación de jugadores, pues los históricos del 70 ya se habían retirado y los nuevos elementos no los llegaron a igualar en talento. Fue recién para las Eliminatorias al Mundial de Francia 1998 que se logró forjar nuevamente un equipo competitivo bajo la dirección técnica del ex mundialista Juan Carlos Oblitas. Perú empató en el cuarto lugar con Chile al final del calendario y quedó excluido de la cita mundialista por la diferencia de goles. Luego de aquella campaña, la selección nacional ha venido fracasando en su intento de conseguir meterse otra vez dentro del torneo de élite, quedando fuera del Mundial para el 2002, 2006, 2010 y 2014. Diversos técnicos, entre nacionales y extranjeros, pasaron por el 
banquillo del equipo sin poder encontrar la "fórmula" para volver a clasificar a un Mundial.

Diversas explicaciones se trazaron desde entonces (García, 2011), empezando por la falta de planificación a todo nivel y visión a corto plazo de dirigentes deportivos, falta de institucionalización de clubes, ausencia de trabajo en divisiones menores, ingentes deudas en el fútbol profesional, escaza preparación psicológica de futbolistas, excesivo rol del periodismo deportivo, presencia de corrupción en distintos estamentos del fútbol, etc.; la situación actual del fútbol en el Perú es aún incierta. No obstante, a pesar de los resultados adversos -en los últimos veinte años- los peruanos (futboleros, se entiende) siguen fervientemente a su selección, llenan los estadios cuando juega de local, lo que revela la importancia que tiene este deporte, independientemente de los resultados que obtenga en la cancha. Y así, cuando aparentemente los resultados le eran esquivos una vez más a la Blanquirroja (como se le conoce a la selección peruana), ésta logró un 2017 espectacular, terminando invicta y consiguiendo un cupo para Rusia 2018 tras 36 años de ausencia a la cita máxima del fútbol internacional. El fútbol, como nunca antes, logró unir simbólicamente a casi todo un país.

\section{Fútbol, identidad y representación}

El deporte y los medios de comunicación tienen una relación simbiótica que se ha intensificado en las últimas décadas, ya que ambos dependen cada vez más unos de otros para su respectiva prosperidad (económica, incremento de audiencias, etc.). El nexo entre ellos, así como su relevancia como instituciones que influyen y dan forma a la opinión pública, hacen que las enunciaciones deportivas sean fuentes interpretativas valiosas para explorar la construcción social de diversos ámbitos de la cultura. Desde luego, estos "textos" (en el sentido amplio del término) se difunden y producen a través de y desde los medios de comunicación masivos y es a partir de ese proceso de interacción entre emisorreceptor que debemos tratar de interpretar dicha dinámica comunicativa. A lo que nos referimos es a tomar consciencia de que esta producción de sentidos a través de los medios no está exenta de la representación ideológica y es en ello donde algunas de las investigaciones en nuestro país han hecho foco.

El análisis de la ideología ofrece una perspectiva valiosa y herramientas útiles para evaluar el poder de las representaciones mediáticas en el Perú contemporáneo. Brinda luces sobre el rol no coercitivo del poder de las representaciones para modelar ideas y formas de pensar. De hecho, hay que anotar que las representaciones apelan muchas veces a nuestros deseos, fantasías y propios intereses, y en ese proceso se naturalizan. En sentido, el principal hilo conductor de muchas de las pesquisas realizadas en el ámbito del fútbol para el caso peruano es revelar cómo las representaciones de los medios se refieren a la forma en que constituyen fuentes y sitios de significado abierto y cambiante para la identidad nacional.

En la actualidad, como sostienen Crolley y Hand (2002: 8), 
...el papel que desempeñan las representaciones mediáticas del fútbol en la construcción de identidades nacionales no puede ser sobrestimado. La nacionalidad se desarrolla, moldea, e incluso se inculca por los medios de comunicación, lo que contribuye al mantenimiento de un conjunto de valores culturales compartidos que sirven para reforzar una percepción consensual de la unidad nacional.

En definitiva, el poder de las representaciones radica en la creación de imágenes, relatos y sensaciones que se convierten en los recursos que dan forma a lo que sabemos y llegamos a saber sobre el mundo. El poder de las representaciones de los medios reside en la producción de recursos simbólicos que alimentan la imaginación individual y colectiva.

Partiendo del conocimiento planteado por diversos teóricos del periodismo deportivo (Rowe, 2004; Boyle y Haynes, 2009; Boyle, 2012) respecto a la función que éste cumple en la sociedad actual, comulgamos con la idea de ponderar el proceso de mediación de la información con el deporte donde "sus discursos de conexión en el campo de la política, la economía y la cultura ofrecen, en general, ricas e iluminadoras avenidas en la relación entre medios y sociedad y las estructuras de poder que configuran e influyen en nuestra existencia cotidiana" (Boyle, 2012: 89). En ese sentido, podemos afirmar que las enunciaciones deportivas no solo comunican información sobre sí mismas, sino también sobre la cultura en su conjunto. Por ejemplo, un reportaje sobre un partido que involucre a la selección nacional peruana podría tomar la forma de un artículo sobre el mundo del deporte internacional, pero su contenido está inextricablemente unido a procesos filosóficos, culturales e ideológicos más amplios. Por lo tanto, también proporciona información sobre el concepto de peruanidad en sí.

\section{Trazando la cancha: la historiogra- fía del balompié y los medios}

A pesar de que la especialidad deportiva ya tenía cabida en las páginas de los principales diarios desde las primeras décadas del siglo XX, el Círculo de Periodistas Deportivos del Perú no se funda hasta el 20 de octubre de 1941. Según apunta Álvarez (2013: 224), sus primeros directivos fueron el ex futbolista Mario de las Casas (encargado de la página de deportes del diario La Prensa), Óscar Paz (del diario La Crónica) como vicepresidente y José León Cunza (también de La Crónica) como tesorero. En sus inicios, la Federación Peruana de Fútbol (FPF) y la Asociación Nacional de Fútbol brindaron apoyo para amoblar su local según relata el propio De las Casas en el Libro de Oro del Círculo de Periodistas.

El interés por el deporte -en especial por el fútbol- empezó a crecer en los aficionados y prueba de ello es la gran cantidad de revistas deportivas que circularon a mediados del siglo pasado en la capital $^{4}$. Quizá este fenómeno fue la semilla que inició el impulso por investigar

4 Entre las principales revistas deportivas de la época podemos mencionar a Mundo Deportivo, Mundo Gráfico, Sport y Golazo. 
al periodismo deportivo como una disciplina específica, separada de la gran prensa generalista. Como se conoce, aún en aquella época no existía en las universidades la carrera de Periodismo ${ }^{5}$, por lo que la mayoría de periodistas deportivos de ese entonces eran ex deportistas u personas que habían estudiado alguna carrera de letras como Derecho o Filosofía.

\subsection{Primeras pesquisas}

Es recién a finales de los 60 e inicios de los 70 que podemos ubicar los primeros trabajos académicos sobre prensa deportiva en el Perú. Fueron pioneros en este campo las tesis de grado de Best (1969) y Ganoza (1973), de la Universidad San Martín de Porres y Cabrera (1974) de la EPUC. Este grupo de autores coinciden en realizar un diagnóstico del panorama del periodismo deportivo peruano de su época, ofreciendo mejoras y resaltando el rol que el deporte venía cobrando en la sociedad peruana de la década del 60 y 70 . Se trata, en definitiva, de trabajos más evaluativos y ponderativos de la situación de esta especialidad y no tanto de ejercicio analítico e interpretativo sobre el fenómeno deportivo.

En la década del 80 siguen sustentándose más tesis sobre la materia, tales como los aportes de Romero (1986) y su trabajo sobre prensa deportiva y el sensacionalismo y Ponce (1988) con un análisis de la información escrita en la prensa generalista. Es relevante notar que ya desde estos años los investigadores detectaban un estilo propio en el discurso periodístico deportivo, muy similar a la de los tabloides o prensa popular como La Crónica o Última Hora. Recordemos que estas pesquisas se desarrollaban aún sin la presencia de los periódicos especializados en información deportiva, que surgen recién en la década de 1990.

\subsection{Masificación del fútbol y de la in- formación deportiva}

Durante la segunda mitad de los 90 se diversifican los trabajos. La tesis de Queneche (1995) analiza la cobertura de la información deportiva en un diario de circulación masiva y aporta interesantes conclusiones sobre el estilo del lenguaje deportivo. Quezada (1999), en el especial sobre fútbol de la revista Contratexto, también se decanta por el análisis del estilo del lenguaje deportivo desde una perspectiva semiótica. Mientras que García (1998), en ensayo compilado en el libro Deporte y Sociedad, aborda los vínculos entre el fútbol y el negocio de la televisión, presentando una interesante revisión acerca de la importancia de este deporte como negocio, tomando en cuenta los auspicios que ya desde los 90 empezaban a recibir los clubes peruanos por la televisación de sus partidos y la publicidad en sus camisetas.

5 La primera universidad en impartir la carrera de Periodismo fue la Pontificia Universidad Católica del Perú, que inauguró su Escuela de Periodismo (EPUC) en marzo de 1945. 
A inicios del nuevo milenio, la tesis de Rodríguez (2003) realiza un estudio de un conocido portal web de deportes durante los primeros años de la llegada del Internet a nuestro país. Zenteno (2004), también en su trabajo de grado, enlaza al fútbol con la publicidad a fin de identificar las principales características de los patrocinadores de los equipos de fútbol profesionales. Para finales de la década, el seminal libro Ese gol existe (editado por el sociólogo Aldo Panfichi), recoge testimonios reveladores acerca de dos periodistas deportivos del siglo XX que, en palabras del autor, fueron los fundadores de esta disciplina en el Perú. Se trata de las historias de vida de Víctor Andrés Rodríguez Leiva (más conocido como Varleiva) y de Littman Gallo "Gallito". Ambas historias, a cargo del propio Panfichi (2008) y Arias Schreiber (2008), nos permiten adentrarnos a la historia del periodismo deportivo peruano a través de sus propios protagonistas. Así, ellos cuentan su paso por los principales medios deportivos del siglo XX, tanto en prensa escrita, radio y televisión. Estos escritos son un testimonio valioso para los futuros periodistas deportivos, pues les permiten conocer las dificultades que aquejaban a una profesión ciertamente periférica (en el sentido de Bourdieu).

\subsection{Racismo y otredad en los discur- sos deportivos}

Otro importante aporte para ponderar el rol de los medios de comunicación deportivos en el Perú son los documentos de trabajo de LUNDU, ONG dedicada la promoción y defensa de los derechos de la cultura afroperuana. Desde 2008, ellos cuentan con un observatorio de medios de comunicación, donde identifican prácticas racistas a través del discurso periodístico. En diversas publicaciones de carácter divulgativo (LUNDU, 2008; 2009; 2010; 2012; 2014) esta institución se ha encargado de revelar la manera en que la prensa -particularmente la escrita- naturaliza prácticas racistas a través de sus discursos. Una importante muestra de estas malas prácticas proviene de los diarios especializados en información deportiva, que continuamente -a través de estereotipos raciales o jergas- denuestan a la comunidad afroperuana. LUNDU se encarga de hacer visibles estas prácticas racistas con un fin informativo y de cambio de mentalidad en nuestra comunidad.

También desde el propio Estado peruano, a través del Ministerio de Cultura, se han publicado estudios sobre este tipo de experiencias racistas. El MINCUL (2016), en informe elaborado por el periodista Gonzalo Silva Infante, pone en relieve los principales discursos racistas encontrados en la prensa escrita para el lapso 2013-2015, obteniendo además los testimonios de los propios futbolistas afectados, dirigentes, árbitros y periodistas. Gonzáles (2017), en una ponencia presentada al Congreso LASA, hace foco en la forma en que se representó en la prensa deportiva peruana el caso de discriminación racial del jugador brasileño Tinga en un partido por la fase de grupos de la Copa Libertadores. De esta presentación se revela cómo a los jugadores afrodescendientes se les 
adjudica apodos para animalizarlos o convertirlos en objetos.

\subsection{Televisión, información y presen- cia femenina en los medios deportivos}

Alberto Beingolea (2010), ex congresista de la República, presenta una ponencia sobre el rol de la televisión dentro del contexto de una sociedad donde cada vez más la información deportiva cobra mayor notoriedad. El abogado, con una amplia experiencia en la conducción de espacios deportivos en señal abierta y de cable, discute su paso por la pantalla chica a fin de reflexionar sobre el panorama futuro de la televisión como campo deportivo. Otro trabajo en ese tenor es el de Figueroa (2013), quien analiza en su tesis la producción de programas deportivos con el caso de estudio Planeta Deporte. También el artículo de Salvatori (2013) apunta sus preguntas sobre este medio frente al cual afirma que ya no sólo se trata de un aparato destinado a las transmisiones de eventos deportivos, sino que se ha transformado a través de complejas dinámicas en su relación con la audiencia: ahora la TV también se ha convertido en difusor de modelos de identidad nacional a través de los futbolistas. Muchos de ellos, apunta este investigador, son utilizados en campañas sociales o su figura se vincula a determinados valores positivos que calan en la población con mayor rapidez que cualquier político.

Castillo (2013) y García (2014), desde sus tesis de grado, realizan aportes al campo en cuanto a la producción de noticias en el periodismo deportivo y a las herramientas básicas de los periodistas dedicados a esta disciplina. El estudio de Castillo se aboca al examen de los criterios que rigen la producción de noticias sobre traspasos de jugadores en el periodismo deportivo en el Perú tomando como caso de estudio a uno de los principales diarios deportivos de la actualidad: Depor. Para ello, este autor critica el modo en que el rumor toma protagonismo dentro de esa dinámica, lo que pone en tela de juicio la ética de este medio. García (2014), actual reportero de Movistar Deportes, trabajó sobre el rol que cumple la entrevista periodística en la elaboración de perfiles en prensa deportiva. Es de suponer que este periodista, con muchos años de experiencia entrevistando a deportistas de diversas disciplinas, puede brindar luces respecto a la forma de abordar a los protagonistas de la noticia y convertirlos en personajes de gran relevancia para un potencial reportaje o perfil.

El rol de la mujer en el periodismo deportivo es un tópico que no ha quedado ajeno a la investigación nacional, materializándose en trabajos de fin de grado. Tanto Vargas (2012) como Fernández (2015) examinan la presencia femenina dentro de los principales programas deportivos televisivos actuales. Se trata de trabajos relevantes en cuanto evalúan la estereotipación que sufren las mujeres en la profesión periodística deportiva, donde se les encasilla comúnmente a lugares periféricos dentro de la producción de noticias como redactoras, conductoras de noticieros o reporteras; pero rara vez figuran en posiciones de mayor poder de decisión 
como productoras generales, editoras centrales e incluso panelistas de discusión en programas futbolísticos ${ }^{6}$.

\subsection{Investigaciones sobre clubes y la selección nacional de fútbol}

Una arista importante a considerar es la especial atención que en las últimas décadas se ha colocado desde la Historia al origen y difusión del balompié en nuestro país, así como a la construcción de identidades y rivalidades futbolísticas que fueron surgiendo conforme se asentaba el espectáculo deportivo en ciudades como Lima y el puerto del Callao. La mayoría de estas pesquisas se nutren de fuentes primarias como diarios de la época y algunas revistas especializadas en deportes. De esta forma, es a través del análisis del discurso de los medios impresos que podemos tener acceso a la manera en que se entendía la práctica deportiva en las primeras décadas del siglo XX en el Perú.

Pionero en este campo es Álvarez (2001), a quien ya mencionamos líneas atrás. En su tesis de licenciatura, este académico trabaja sobre las bases de fuentes primarias (no solo diarios, sino también documentos oficiales como decretos de alcaldía, normas, leyes, correspondencias, etc.) para desentrañar los orígenes de la práctica del fútbol en Lima, examinar a las instituciones y clubes que apoyaron y permitieron su propagación en la capital, y revisar los tipos de clubes de fútbol más importantes según su origen social. En un estudio posterior conducente a su grado de doctor (2013), este historiador amplía su mirada y se aboca a analizar la gestación del espectáculo deportivo y la competencia entre equipos de fútbol así como diversos aspectos vinculados a la construcción de identidades tanto locales (Alianza Lima contra Universitario) y nacionales (Selección Nacional y sus campañas en los Campeonatos Sudamericanos de las décadas de 1920 y 30). Para realizar esta tarea utiliza como fuentes los textos de las secciones deportivas de los principales diarios peruanos de la época: El Comercio, $\mathrm{La}$ Prensa y La Crónica.

Pulgar Vidal (2008) ha explorado un tema similar, enfatizando las identidades locales a través de su estudio sobre el origen del clásico del fútbol peruano entre Alianza Lima y Universitario. Este periodista e historiador, en el ensayo publicado en el libro Ese gol existe, descubre cómo a través de este enfrentamiento se revelan clivajes enraizados en la sociedad peruana de las primeras décadas del siglo pasado, tales como la esterotipación de grupos raciales distintos (negros contra blancos) y la discriminación de clase (los jugadores aliancistas eran albañiles y obreros mientras que los de Universitario eran estudiantes). Asimismo, en un estudio posterior para la obtención del grado de magíster en Historia (Pulgar Vidal, 2016), profundiza en la presencia como "padrino"

6 Recientemente Movistar Deportes (señal por cable) ha renovado su programación y cuenta con diversos programas que tienen en sus filas a mujeres periodistas como panelistas de discusión debido a la coyuntura generada por la clasificación de Perú al Mundial. 
(una suerte de auspiciador tanto económico como de prestigio) del presidente peruano de aquel momento, Augusto B. Leguía, que se presentaba con un discurso incluyente para los sectores plebeyos de la sociedad; sirvió, en palabras de Pulgar Vidal, para darle legitimidad al balompié. También examina la construcción de una identidad nacional a partir del estilo de juego de la selección peruana de fútbol en las décadas de 1920 y 30.

Otra rivalidad futbolística tradicional que parte desde la comprensión del estudio de las identidades es nuestro reciente trabajo sobre el denominado clásico del Pacífico entre las selecciones nacionales de Perú y Chile (Pahuacho, 2017c), elaborado para la obtención de nuestra licenciatura en Periodismo. A través del Análisis del Discurso, hicimos foco en la forma en que los diarios peruanos de las décadas de 1930 y 40 representaban la rivalidad con el vecino país del sur a través de diferentes estrategias discursivas tales como la creencia de una supuesta superioridad del estilo del fútbol peruano. No obstante, uno de los hallazgos más relevantes de esta pesquisa es comprobar cómo los periodistas peruanos no utilizaron ninguna alusión al tema bélico (la guerra del Pacífico) ni recurso de denuesto a los chilenos, sino todo lo contrario: los discursos transmitían un clima de amplia camaradería deportiva bajo el legado aún presente del Olimpismo.

Respecto al tratamiento informativo de las campañas recientes de la selección peruana de fútbol, podemos advertir que también se trata de un cam- po de investigación que ha generado gran interés entre académicos vinculados al tema deportivo. Mallma (2009), en un Informe Profesional de la Escuela de Periodismo de la Universidad San Marcos, describe las principales características de los discursos de los diarios deportivos a propósito de la eliminación de la selección al Mundial Alemania 2006. Por su parte Morales (2012), en su tesis, se muestra crítico en cuanto a la información deportiva brindaba por los principales medios deportivos, lamentando que sólo se aboquen casi en exclusividad al fútbol en desmedro de otros deportes. En tanto que Salinas (2015), en un libro editado por el fondo editorial de la Universidad San Martín, también hace médula en los discursos referidos a la selección nacional, identificando las principales características (portada, lenguaje, diseño y fotografía) de los periódicos deportivos que cubrieron a la selección durante la Copa América 2011 y las Eliminatorias 2014. Y la tesis de licenciatura de Li (2014) se aboca al estudio de las estructuras narrativas de las crónicas deportivas y de las fotografías aparecidas en la prensa en la cobertura de la campaña peruana rumbo al Mundial de Brasil 2014.

Un tanto distinta es la óptica que adoptamos en dos papers de aparición reciente. En el primero de ellos, publicado en la Revista Brasileira de Ciencias do Esporte (Pahuacho, 2017a), examinamos los spots televisivos emitidos en la televisión peruana durante las Eliminatorias al Mundial 2014. Allí, discutiendo conceptos de corte psicoanalítico, deconstruímos la ideología que presentaba a la 
selección peruana como una posibilidad de comunión compacta y homogénea entre todos los peruanos, invisibilizando las fracturas y tensiones inherentes de todas sociedad. Mientras que en nuestro análisis de la revista Âncora sobre la campaña peruana en la Copa América Centenario 2016 (Pahuacho, 2017b), incluimos una crítica sociológica y cultural a la sociedad peruana a raíz del polémico gol convertido por el jugador peruano Ruidiaz que a la postre le dio la clasificación al Perú a la siguiente fase del torneo.

\subsection{Héroes del balompié nacional}

El tema de los héroes deportivos no ha sido ajeno al interés académico, especialmente al referirnos a los futbolistas más representativos de la historia peruana. Gonzalo García Bedón (2014), a través de un profundo trabajo de investigación periodística (entre entrevistas y revisión de material periodístico de la época), radiografía la vida del máximo ídolo del club Universitario de Deportes y goleador de la selección peruana de las décadas del 20, 30 y 40: Teodoro Lolo Fernández. Muestra una mirada renovada del recordado cañonero, muy útil en tiempos donde los más jóvenes recuerdan muy poco la historia y orígenes del balompié en nuestro país.

Desde nuestra propia línea de investigación, también hemos analizado a otro referente más contemporáneo, explorando la construcción discursiva del futbolista Paolo Guerrero como símbolo de una supuesta "peruanidad ideal" (Pahuacho 2014; 2015). A través de la revisión del discurso de los principales diarios deportivos, identificamos un paralelo entre los viejos héroes de la guerra del Pacífico (Grau y Bolognesi) con las características que la prensa deportiva actual le enfunda a Guerrero: la valentía y el sacrificio. A través de un Análisis del Discurso, pusimos en tela de juicio la construcción de este futbolista como tipo-ideal de peruano, revelando las fisuras que esconden los propios discursos de la prensa deportiva, que invisiviliza las acciones negativas de Guerrero (rabietas, expulsiones, falta de gol, etc.).

\section{Conclusiones y panorama futuro para el campo}

Nuestra experiencia del fútbol es inevitablemente transmitida por los medios de comunicación deportivos, y una comprensión de la forma en que éstos construyen significados en torno al balompié y las identidades entre su público es fundamental para un compromiso crítico con el deporte. Sin embargo, como fenómeno, el periodismo deportivo siempre está en movimiento, reconfigurando constantemente el fútbol en relación con los contextos y valores sociales. Debido a ello, notamos que en la actualidad existen aún grandes vacíos y temas que no han sido abordados desde la academia peruana, los cuales requerirían mayor profundización en aras de enriquecer este campo interdisciplinar de estudio.

Una arista que aún permanece en las sombras es la historia visual del fútbol peruano. La extensión y naturaleza de la experiencia visual del periodismo 
deportivo todavía no se ha explorado completamente, pero podemos afirmar que nuestra vida social futbolística ha sido construida, desplegada y recibida en gran medida a través de lo visual. El material visual filtra, organiza y edita el pasado y el presente, y crea memorias colectivas e ideales culturales. Además, en las últimas décadas se ha producido un gran aumento no sólo en el número de imágenes sino también en la naturaleza de las imágenes producidas y consumidas (gracias a la TV satelital y el Internet), y éstas nos hablan de diferentes maneras sobre los lenguajes verbales y textual.

Siguiendo este punto, es interesante preguntarse cómo la cultura visual y sus múltiples voces y perspectivas han llegado a modelar nuestras percepciones, engendrar ideologías y subjetividades, e incluso formar narraciones, estereotipos, comportamientos y entendimiento cultural dentro de la sociedad. Abordar las imágenes deportivas desde el concepto de "visualidad" (término que alude al carácter culturalmente construido de la visión) es una tarea aún pendiente dentro de las investigaciones peruanas. Las imágenes pueden ayudar a visualizar el poder social y la diferencia, y esto a su vez moldear el comportamiento social. Desde las fotografías que acompañan a la diagramación de las crónicas en los diarios deportivos (las poses, los gestos, el color, los personajes, etc.) hasta las fotografías publicitarias de los futbolistas más cotizados del medio local, ejemplos sobran para iniciar un análisis desde la crítica visual.
Otra rama interesante para abordar el ámbito del fútbol podría ser la semiótica. Esta disciplina explora no sólo lo que el material visual puede "significar" sino que enfatiza cómo el emisor, el receptor y la sociedad en general construyen cotidianamente esos significados. Su enfoque son los signos dentro de las imágenes, sus códigos, mitologías, ideologías o sistemas más amplios de significado de grupos específicos, y sus interrelaciones. También la imagen misma, su estructura y características compositivas, y las maneras en que construye y forma efectos tales como la diferencia social, están en el centro del análisis. Una aproximación semiótica tradicional al tema futbolístico podría abordar spots publicitarios analizando niveles connotativos y denotativos o metáforas difundidas en el aviso. Otro material de estudio interesante podrían ser posters $o$ afiches impresos sobre clubes o la misma selección nacional.

Los estudios de audiencias y recepción son muy importantes dentro del campo interdisciplinario del deporte aunque en nuestro país no han sido abordados. El trabajo empírico es actualmente más influyente e informativo, a pesar de los grandes desafíos y ambiguas complejidades de establecer la interpretación y las mentes de los aficionados pueden ser exploradas a través de la historia oral. Es posible indagar cómo la gente lee y responde a los textos deportivos de los medios de comunicación de diferentes maneras en relación con sus orígenes e identidades sociales. La relación entre la imagen y los espectadores, las diferencias entre 
los grupos de espectadores, las distintas maneras de "leer" la imagen, la convención que siguen y su comportamiento mientras se ven son temas potenciales para la academia peruana.

Muy poco se ha explorado desde el lenguaje académico del rol de las instituciones -públicas o privadas- que generan ganancias a través del negocio del fútbol en el Perú ${ }^{7}$. En casos como Europa o Asia, el apoyo de los gobiernos nacionales fue clave para el desarrollo de la televisión o radio deportiva, mientras que en otros países como EE.UU el auge futbolístico provino gracias al apoyo de franquicias de empresas privadas (Whannel, 1992). Se necesita un capital considerable para organizar eventos deportivos en vivo o para incluso emplear periodistas. En algunos casos, el Estado ha asumido el costo de los primeros (como los recientes Panamericanos de Lima o más atrás, la Copa América de 2004) porque el deporte es uno de los vehículos más poderosos y relativamente pacíficos para representar a la nación y mantener "temporalmente" unidos a los grupos heterogéneos de un país.

Enfatizando el tema de la forma de producción y estilo del campo televisivo y radial, si bien se cuenta con algunos aportes, este carece aún de investigaciones históricas referidas a la manera en que se desarrollaban las transmisiones en las décadas pasadas, especialmente las del 70 y 80 que es cuando la selec- ción peruana clasificó a varios mundiales de forma consecutiva y se consagró campeón de América. ¿Cómo era el estilo de los narradores de los partidos en aquella época? ¿Imperaba el nacionalismo deportivo, usos de frases cliché? Son preguntas aún por responder. En el caso de las convenciones de representación, la apariencia, el sonido y el registro del balompié presentados a través de los medios de comunicación varían sustancialmente de acuerdo a donde se ha producido y cuáles eran las expectativas de la época. Junto a las transmisiones, también podrían estudiarse los antiguos programas deportivos que se transmitían por televisión, tales como Gigante Deportivo, Afición Deportiva, El show del deporte, Minuto 91, Goles en acción, entre otros.

Refiriéndonos al aspecto geográfico de las pesquisas discutidas, la mayoría de académicos peruanos se centran exclusivamente en Lima (programas televisivos y diarios limeños), por lo que es necesario diversificar la muestra a través del examen de diarios provincianos deportivos (o generalistas con sección deportiva) así como a la producción de programas en televisión hechos fuera de la capital. Uno de los medios masivos de comunicación que muestra una ausencia de un estudio específico sobre programas en su tipo es la radio. La radio fue el primer discurso hablado sobre el fútbol al que tuvo acceso la gente, con las transmisiones de los primeras

7 Se han publicado algunas notas periodísticas en el diario Gestión referidas a los sueldos de futbolistas, patrocinios y taquillas. 
Copas del Mundo y los Campeonatos Sudamericanos que se organizaban a las afueras de los locales de los principales diarios limeños (Álvarez, 2013). Además, a mediados del siglo pasado, diversos programas radiales dedicados exclusivamente al deporte eran de los más sintonizados, tales como Pregón Deportivo, Deportegrama y Ovación. Se hace, pues, necesario un trabajo que recoja y ponga en valor a la radio como difusor de información deportiva, tanto al medio en sí como a los periodistas que hicieron posible tal sinergia, como el recordado "Pocho" Rospligiosi y Óscar Artacho.

Otro campo de estudio aún sin explorar es el de las publicaciones deportivas de la primera mitad del siglo XX. Algunos trabajos recientes como los de Álvarez (2013) recogen de manera sucinta las principales revistas que circularon en épocas pasadas (como Ovación y Mundial), pero no se detienen a examinar su estilo narrativo ni a cuestiones vinculadas con sus características (fotografía, portadas, diseño, etc.). Tampoco existen estudios lingüísticos sobre las publicaciones deportivas, ni pasadas ni actuales. La lingüística es una disciplina que puede ayudar a demostrar propiedades específicas en cuanto al uso del léxico de las publicaciones y también cómo se representa cierto tipo de ideología a través de la selección de un determinado vocablo o frase. En países como Argentina o Chile sí existen pesquisas al respecto como en los casos de las tradicionales revistas El Gráfico (Archetti, 1995) y Estadio (Santa Cruz, 2012).
En los estudios mediáticos -con su interés seminal en el poder de los mensajes difundidos a audiencias grandes, diversas y heterogéneas- el fútbol suele ser visto como un vehículo popular para transmitir significados sociales, mitos e ideologías. Partiendo de las aristas ya mencionadas -prensa escrita, radio y televisión- es posible insistir por un abordaje más teórico y profundo a los investigadores peruanos, tomando en consideración que muchos de los trabajos revisados apenas se quedan en la superficie y se limitan a lo descriptivo. Algunas nuevas rutas podrían apuntar a una crítica del poder mediático de la industria deportiva apostando por una serie de posiciones teóricas, como la teoría de la hegemonía inspirada en el marxismo, los análisis foucaultianos del discurso de los medios de comunicación, las críticas feministas del orden de género que los medios de comunicación promueven, y la teoría racial crítica sobre la complicidad de los medios de comunicación con la estratificación e ideología racistas (O’Shaughnessy \& Stadler, 2008).

Las pesquisas desde los medios no han creado un solo cuerpo de conocimiento con respecto al balompié que constituyan un conjunto claramente delineado de parámetros y un proceso consensual y evolutivo de desarrollo disciplinario. En su lugar, éste consiste en mayor medida en un conjunto de preocupaciones sobre las relaciones entre el fútbol, los medios de comunicación y la sociedad. Existe un amplio consenso de que el fútbol y los medios de comunicación se han transformado 
mutuamente, pero algunos cuestionan si su relación constituye una codependencia más o menos igualitaria o, como es más común, la colonización y la dominación del deporte por los medios de comunicación se está volviendo cada vez más íntima, pero también está sujeta a períodos de crisis que son análogos a los problemas apremiantes en las esferas más amplias de la sociedad, la cultura, la economía y la política (Rowe, 2004).

Este ensayo apenas ha esbozado algunos trazos en la superficie de un tema de rápido crecimiento y extremadamente complejo, del cual las metodo- logías expuestas aquí forman sólo una pequeña parte. Necesitamos más críticas detalladas sobre las premisas, suposiciones y prácticas de los estudios del fútbol y medios de comunicación, incluyendo los de este trabajo. Tenemos que mirar las imágenes y discursos con más cuidado y tener en cuenta su producción y sus aspectos tecnológicos, así como sus elementos de composición. Tenemos que considerar su condicionamiento social y especialmente las cuestiones de acceso y poder, como la clase, la raza, el sexo o la sexualidad y sus efectos. Y necesitamos ser reflexivos en esa mirada.

\section{Bibliografía}

Álvarez, G. (2001). La difusión del fútbol en Lima. (Tesis de licenciatura). Universidad Nacional Mayor de San Marcos, Lima.

Álvarez, G. (2013). Espectáculo deportivo y formación de identidades en el fútbol. Lima primera mitad del siglo XX. (Tesis de doctorado). El Colegio de México, México D.F.

Aguirre, C. (2013). Perú campeón: fiebre futbolística y nacionalismo en 1970. En: Aguirre, C. \& Panfichi, A. (Eds.), Lima siglo XX. Cultura, socialización y cambio (pp. 383-416). Lima: PUCP.

Archetti, E. (1995). Estilo y virtudes masculinas en El Gráfico: la creación del imaginario del fútbol argentino. Desarrollo Económico, vol. 35 (139), oct. - dic. 1995, pp. 419-442.

Arias Schreiber, L. (2008). Cincuenta años de prensa deportiva en el Perú con Litman Gallo, "Gallito". En Panfichi, A. (Ed.), Ese gol existe. Una mirada al Perú a través del fútbol (pp. 283307). Lima: PUCP.

Beingolea, A. (2010). La televisión como espacio deportivo. En Cassano, G. (Ed.), Televisión: 14 formas de mirarla (pp. 81-89). Lima: PUCP.

Best, A. (1969). Contribución al estudio y especialización del periodismo deportivo. (Tesis de doctorado). Universidad San Martín de Porres, Lima.

Boyle, R., \& Haynes, R. (2009). Power Play. Sport, the Media and Popular Culture. Edinburgh: Edinburgh University Press.

Boyle, R. (2012). Reflections on communication and sport: on journalism and digital culture. Communication \& Sport, 1(1/2), pp. 88-99.

Cabrera, A. (1974). La necesidad de un mejor periodismo deportivo en el Perú. (Tesis de licenciatura). Pontificia Universidad Católica del Perú, Lima.

Castillo, R. (2013). Criterios que rigen la producción de noticias sobre los fichajes de futbolis- 
tas profesionales en el Perú: el caso del diario Depor. (Tesis de licenciatura). Pontificia Universidad Católica del Perú, Lima.

Círculo de Periodistas Deportivos del Perú (1991). Libro de oro: 50 años. Lima: El Círculo.

Crolley, L., \& Hand, D. (2002). Football europe and the press. London: Frank Cass.

Eslava, J. (2011). Bien Jugado. Las patadas de una ilusión. Lima: Aguilar.

Fernández, M. (2015). Rol de la mujer en el periodismo deportivo. Canal CMD. (Tesis de licenciatura). Universidad Jaime Bausate y Meza, Lima.

Figueroa, F. (2013). La producción de programas deportivos en el canal del Estado. El caso de Planeta Deporte periodo 1998 - 2003. (Tesis de licenciatura). Universidad Nacional Mayor de San Marcos, Lima.

Ganoza, R. (1973). El periodismo deportivo en el Perú. (Tesis de licenciatura). Universidad San Martín de Porres, Lima.

García, E. (2011). Un acercamiento al deporte y al fútbol como negocio y al funcionamiento, problemática y mejora del fútbol peruano. Journal of Business, vol. 3(2), pp. 79-107.

García, G. (2014). La camiseta de Lolo. Un futbolista a quien no le seducía el dinero. Lima: Mesa Redonda.

García, J. (1998). iSalud! Por la pelota en la pantalla. Sobre cerveza, fútbol y TV. En Alabarces, P., Di Giano, R. \& Frydenberg, J. (Comp.), Deporte y Sociedad (pp. 115-124). Instituto de Investigaciones Gino Germani, Buenos Aires.

García, P. (2014). La entrevista como factor decisivo para elaborar perfiles en prensa deportiva. (Tesis de licenciatura). Universidad de Lima, Lima.

González, S. (Abril de 2017). ¿El perdón o la sanción? Discurso sobre el racismo de la prensa escrita deportiva peruana a través del caso Tinga. LASA Congress. Congreso llevado a cabo en Lima, Perú.

Li, J. (2015). Estructura narrativa de las eliminatorias Brasil 2014 a través de la prensa y sus fotografías. (Tesis de licenciatura). Universidad de Lima, Lima.

LUNDU: Centro de Estudios y Promoción Afroperuanos (2008). Presencia de los afrodescendientes en los medios impresos en el año 2008. Lima: LUNDU.

LUNDU: Centro de Estudios y Promoción Afroperuanos (2009). Observatorio Afroperuano: Medios de Comunicación y Políticas Públicas. Lima: LUNDU.

LUNDU: Centro de Estudios y Promoción Afroperuanos (2010). Observatorio Afroperuano. Lima: LUNDU.

LUNDU: Centro de Estudios y Promoción Afroperuanos (2012). Observatorio Afroperuano 2. Lima: LUNDU.

LUNDU: Centro de Estudios y Promoción Afroperuanos (2014). Observatorio Afroperuano de Medios de Comunicación. Lima: LUNDU.

Mallma, M. (2009). Prensa deportiva y sensacionalismo: el caso del diario Líbero y la eliminación de la selección peruana del mundial de fútbol, Alemania 2006. (Tesis de licenciatura). Universidad Nacional Mayor de San Marcos, Lima.

Ministerio de Cultura. (2016). Casos de racismo en el fútbol (2013-2015). Una mirada desde sus protagonistas. Lima: Ministerio de Cultura del Perú. Disponible en: 
http://centroderecursos.cultura.pe/es/registrobibliografico/

casos-de-racismo-en-el-f\%C3\%BAtbol-2013-2015-una-mirada-desde-sus-protagonistas

Morales, F. (2012). La información deportiva incompleta y limitada de los diarios especializados Los casos de El Bocón, Líbero y Todo Sport. (Tesis de licenciatura). Universidad Nacional Mayor de San Marcos, Lima.

O’Shaughnessy, M \& Stadler, J. (2008). Media and society: An introduction (4th ed.). Melbourne: Oxford, UK University Press.

Pahuacho, A. (2014). El tópico sacrificial en los discursos de la prensa deportiva en el Perú. El caso del futbolista Paolo Guerrero. Correspondencias \& Análisis, vol. 4, pp. 153-175. Disponible en: http://www.correspondenciasyanalisis.com/es/pdf/v4/pe/2_topico_sacrificial.pdf

Pahuacho, A. (2015). El fútbol y el héroe posmoderno. Conexión, vol. 4, pp. 50-64. Disponible en: http://revistas.pucp.edu.pe/index.php/conexion/article/view/14974

Pahuacho, A. (2017a). La patria televisada: la representación de la peruanidad en dos comerciales rumbo al Mundial Brasil 2014. Revista Brasileira de Ciencias do Esporte, vol. 39 (2), abril-junio, pp. 206-213. Disponible en: http://www.sciencedirect.com/science/article/pii/ S0101328915300044

Pahuacho, A. (2017b). Representación discursiva de un triunfo en el periodismo deportivo: Brasil versus Perú en la Copa América Centenario 2016. ÂNCORA - Revista Latinoamericana de Jornalismo, año 4, vol. 4 (1), pp. 88-112. Disponible en: http://periodicos. ufpb.br/ojs/index.php/ancora/article/view/35848/18218

Pahuacho, A. (2017c). La representación de la rivalidad futbolística Perú/Chile en la prensa escrita peruana. Análisis de los diarios El Comercio, La Prensa y La Crónica (1935-1947). (Tesis de licenciatura). Pontificia Universidad Católica del Perú, Lima.

Panfichi, A. (2008). Don Varleiva: memorias de una época. En Panfichi, A. (Ed.), Ese gol existe. Una mirada al Perú a través del fútbol (pp. 271-282). Lima: PUCP.

Ponce, G. (1988). Periodismo deportivo en el Perú: información deportiva en la prensa escrita. (Tesis de licenciatura). Universidad de Lima, Lima.

Pulgar Vidal, J. (2008). A bastonazo limpio: la historia del primer clásico del fútbol peruano. En Panfichi, A. (Ed.), Ese gol existe. Una mirada al Perú a través del fútbol (pp. 111-134). Lima: PUCP.

Pulgar Vidal, J. (2016). Selección Nacional de 'Fulbo'1911-1939. Fútbol, Política y Nación. (Tesis de maestría). Pontificia Universidad Católica del Perú, Lima.

Queneche, P. (1995). Tratamiento y cobertura informativa de las secciones deportes, local, policial, judicial del diario El Tiempo. (Tesis de licenciatura). Universidad de Piura, Piura. Quezada, O. (1999). Apuntes para una formación semio-narrativa del discurso (del) fútbol. Contratexto, número 12, pp. 163-178. Disponible en: http://revistas.ulima.edu.pe/index. $\mathrm{php} /$ contratexto/article/view/727

Rodríguez, I. (2003). DELGOL.COM: desarrollo, lanzamiento, puesta en marcha y dirección de un portal "Sui Generis". (Tesis de licenciatura). Universidad de Lima, Lima.

Romero, E. (1986). Ética y prensa deportiva sensacionalista: condicionamiento y motivación 
a través del deporte. (Tesis de licenciatura). Universidad San Martín de Porres, Lima. Rowe, D. (2004). Sport, Culture and the media. The unruly trinity. Glasglow: Open University.

Salinas, C. (2015). Prensa y fútbol en el Perú. La selección nacional en los tabloides deportivos. Lima: USMP.

Salvatori, P. (2013). El deporte en la televisión. La mirada de Télemo, número 9, pp. 1-10. Disponible en: http://revistas.pucp.edu.pe/index.php/lamiradadetelemo/article/ view/5818/5812

Santa Cruz, E. (2012). Prensa deportiva y desarrollismo en Chile. El caso de la revista Estadio. Mapocho, № 71, 1er. Semestre. DIBAM, pp. 261-283.

Vargas, M. (2012). Análisis de la imagen de las mujeres en la programación televisiva transmitida en Lima. CONCORTV Blog Mediática, pp. 1-19.

Whannel, G. (1992). Fields in visión: Television sport and cultural transformation. London: Routledge.

Zenteno, G. (2004). El fútbol, una máquina publicitaria: patrocinio deportivo en el fútbol peruano. (Tesis de licenciatura). Pontificia Universidad Católica del Perú, Lima. 